\title{
Evaluation of Tigecycline Efficacy and Post-Discharge Outcomes in a Clinical Practice Population with Complicated Intra-Abdominal Infection: A Propensity Score-Matched Analysis
}

\author{
Joseph Solomkin, C. Daniel Mullins, Alvaro Quintana, ${ }^{3}$ Christian Eckmann, ${ }^{4}$ Ahmed Shelbaya, \\ Frank R. Ernst, ${ }^{6}$ Michelle R. Krukas, and Arlene Reisman ${ }^{8}$
}

\begin{abstract}
Background: The utility of tigecycline as compared with other antibiotic therapies in the treatment of patients with complicated intra-abdominal infection (cIAI) and the short- and long-term outcomes of a large cohort of severely ill patients were examined. We provide the first published data on post-discharge events for these patients.

Methods: Retrospective data for the cIAI cohort were obtained from a large clinical database. Patients aged $\geq 18$ y were selected for inclusion based on hospitalization with a relevant diagnosis code and procedure code, and guideline-compliant antimicrobial therapy. Propensity scoring was used to reduce treatment-selection bias introduced by the use of observational data. Tigecycline patients were placed into quintiles based on propensity score and were matched 1:3.

Results: The final model based on propensity score matching included 2,424 patients: Tigecycline $(\mathrm{n}=606)$ and other antibiotic therapy $(n=1,818)$. Treatment was successful in $426(70.3 \%)$ tigecycline-treated patients and in $1,294(71.2 \%)$ patients receiving other antibiotics. Similar treatment success occurred across all infection sites. Among survivors, treatment failure was associated with a greater need for all-cause re-hospitalization at $30 \mathrm{~d}$ and $180 \mathrm{~d}$. No differences in cIAI-related re-hospitalization and discharge status were observed.

Conclusions: Using propensity scores to match populations, similar outcomes were demonstrated between treatment with tigecycline and other antibiotics as expressed by treatment success, the need for re-admission, similar 30-d discharge status, and the need for re-admission at $180 \mathrm{~d}$.
\end{abstract}

$\mathbf{C}$ OMPLICATED INTRA-ABDOMINAL INFECTIONS (CIAI) with high severity are associated with poor prognosis. Cure and survival are determined by anatomic extent of disease (peritonitis vs. abscess); physiologic severity, age, and comorbidities; diagnostic delay and therapy; and inappropri- ate application of other elements of care. The development of computed imaging, percutaneous abscess drainage, and minimally invasive operative procedures has substantially altered the management of these infections. These technologic advances have led to improved outcomes from

${ }^{1}$ University of Cincinnati College of Medicine, Cincinnati, Ohio.

${ }^{2}$ Pharmaceutical Health Services Research, University of Maryland School of Pharmacy, Baltimore, Maryland.

${ }^{3}$ Medicine Development Group, Pfizer Inc, Collegeville, Pennsylvania.

${ }_{5}^{4}$ Klinkum Peine Academic Hospital of Medical University Hannover, Peine, Germany.

${ }^{5}$ Columbia School of Public Health, New York, New York.

${ }^{6}$ Indegene TTM, Kennesaw, Georgia.

${ }^{7}$ Quintiles, Cambridge, Massachussetts.

${ }^{8}$ Global Innovative Pharma Business, Pfizer Inc, New York, New York.

Presented at the Thirty-fourth Annual Meeting of the Surgical Infection Society, Baltimore, Maryland, May 1-3, 2014.

(C) Joseph Solomkin et al. 2016; Published by Mary Ann Liebert, Inc. This Open Access article is distributed under the terms of the Creative Commons Attribution Noncommercial License (http://creativecommons.org/licenses/by-nc/4.0/) which permits any noncommercial use, distribution, and reproduction in any medium, provided the original author(s) and the source are credited. 
infections caused by perforations in the gastrointestinal tract [1-3].

Tigecycline, an intravenous broad-spectrum glycylcycline antimicrobial agent, is approved for use in the United States for the treatment of cIAI as well as complicated skin and skin structure infections and community-acquired bacterial pneumonia [4]. As the product label includes a black box warning highlighting an increase in all-cause mortality rates in tigecycline-treated patients as compared with those receiving a comparator treatment based on a meta-analysis of clinical trial data, it should be noted that tigecycline use should be reserved for cases when alternative agents are not suitable [4]. The cause of the increased mortality rates has not been established.

Clinical registration trials for investigational antibiotics for cIAI typically enroll patients with moderate severity of infection and illness, particularly perforated appendicitis, with minimal anticipated morbidity, and mortality rates below 5\%. Translation of phase 3 registry antibiotics trials to clinical practice has been questioned. Recently published data regarding the use of tigecycline in severely ill patients (mean Acute Physiology and Chronic Health Evaluation [APACHE] II score 16.9) showed favorable results in terms of clinical outcome [5]. Nevertheless, because of the design of the study, the interpretation of these data is hampered by the lack of a comparator.

Other surveys of cIAIs, as encountered in clinical practice, do carry substantial risk of morbidity and death. Recent broad surveys have indicated a mortality rate of $10 \%[6,7]$ with morbidity and mortality rates closely tied to sepsis syndromes and uncontrolled infection. Further, the post-discharge outcome of patients cured of cIAI has not been specifically explored. Outcomes research on other acutely infected patient groups suggests frequent re-admissions for multiple infectious and non-infectious problems [8].

To evaluate short- and long-term outcomes in a group of seriously ill patients with cIAI, we conducted a retrospective, observational study using a large clinical practice database to examine the effectiveness of tigecycline use compared with other antibiotic therapies in the treatment of patients with cIAI. This provided the opportunity to examine the utility of propensity score matching in these observational trials and the short- and long-term outcomes of a large cohort of severely ill patients.

\section{Patients and Methods}

\section{Study design}

The retrospective data for the cIAI cohort were obtained from the database maintained by the Premier, Inc. (Charlotte, NC) between January 2009 and June 2012. The database contains de-identified patient data from more than 600 nonfederal acute care hospitals accounting for one in five hospital discharges in the United States. De-identified data collected included hospital discharge files, patient demographics, disease state information, and date-stamped patient-level logs of billed items, including procedures, medications, laboratory, and diagnostic and therapeutic services.

Patients aged $\geq 18 \mathrm{y}$ were identified for inclusion in the analysis based on relevant International Classification of Diseases, Ninth Revision, Clinical Modification (ICD9-CM) diagnosis and procedure codes indicative of cIAI
(Appendix Table 1), and treated with antibiotic therapy considered appropriate in recent guidelines [3]. Index hospitalizations for cIAI occurred during the study period with no hospitalizations for cIAI within $30 \mathrm{~d}$ prior to the index admission. Only the first qualified admission was included for a particular patient. Patients were grouped into cohorts according to antibiotic use-tigecycline (monotherapy or in combination) or other antibiotic therapy. Because of the similarities in gram-negative spectrum and use in cIAI, a separate cohort of patients treated with tigecycline and of patients receiving imipenem-cilastatin was also included. Antibiotic administration was to have occurred for up to $2 \mathrm{~d}$ before the first cIAI procedure, on the day of the first cIAI procedure (index date), and for at least 2 consecutive $\mathrm{d}$ immediately following the surgical procedure. The observation period included the $30 \mathrm{~d}$ prior to index hospitalization, index admission time period, and the $30 \mathrm{~d}$ and $180 \mathrm{~d}$ following discharge from the index hospitalization. Because of the small number of imipenem-cilastatin-treated patients, adequate propensity score matching could not be performed between tigecycline and imipenem-cilastatin patients.

\section{Outcome definitions}

The health outcome of primary interest was measured by a composite binary variable (treatment success or failure). Treatment success was defined as one of two scenarios: (1) The patient was alive for at least $30 \mathrm{~d}$ following the index date, if still in the hospital; (2) the patient was discharged alive within $30 \mathrm{~d}$ of the index date without requiring a second surgical intervention related to the cIAI. If neither of those conditions was present the case was considered a treatment failure.

Hospital length of stay (LOS) was defined as the total number of $\mathrm{d}$ in the hospital as an admitted patient. Intensive care unit (ICU) LOS was defined as the number of $d$ that a patient received any treatment in the ICU, identified using charge master items for ICU room and board.

Re-admission was defined as a new admission following discharge from the index hospitalization. These were limited to patients who did not die within the prior hospital stay, and to subsequent admissions to the same facility; admissions of patients to different facilities are not identifiable in the Premier database because each hospital uses its own unique patient identifier. Complicated IAI-related re-admission was identified when the re-admission data provided evidence of cIAI as the main reason for that additional stay, whereas any re-admission regardless of reason was counted among the allcause re-admissions.

\section{Statistical analysis}

Descriptive analysis was used to describe the characteristics of the cIAI cohort. The Charlson Comorbidity Index (CCI) was used to score the patient's health status [9]. This index provides a risk of death for subjects in longitudinal studies based on comorbid diseases. Scores were grouped as $0,1,2,3$, and $\geq 4$ (greater scores correlate to a lower probability of survival). The $3 \mathrm{M}^{\mathrm{TM}}$ All Patient Refined ${ }^{\mathrm{TM}}$ Diagnosis Related Group (APR-DRG) Classification System was used to adjust for severity of illness (SOI) and risk of mortality (ROM) allowing for the further characterization of health status [10]. The APR-DRG system is algorithm-based and takes into consideration ICD-9 diagnosis, age, gender, discharge data, 


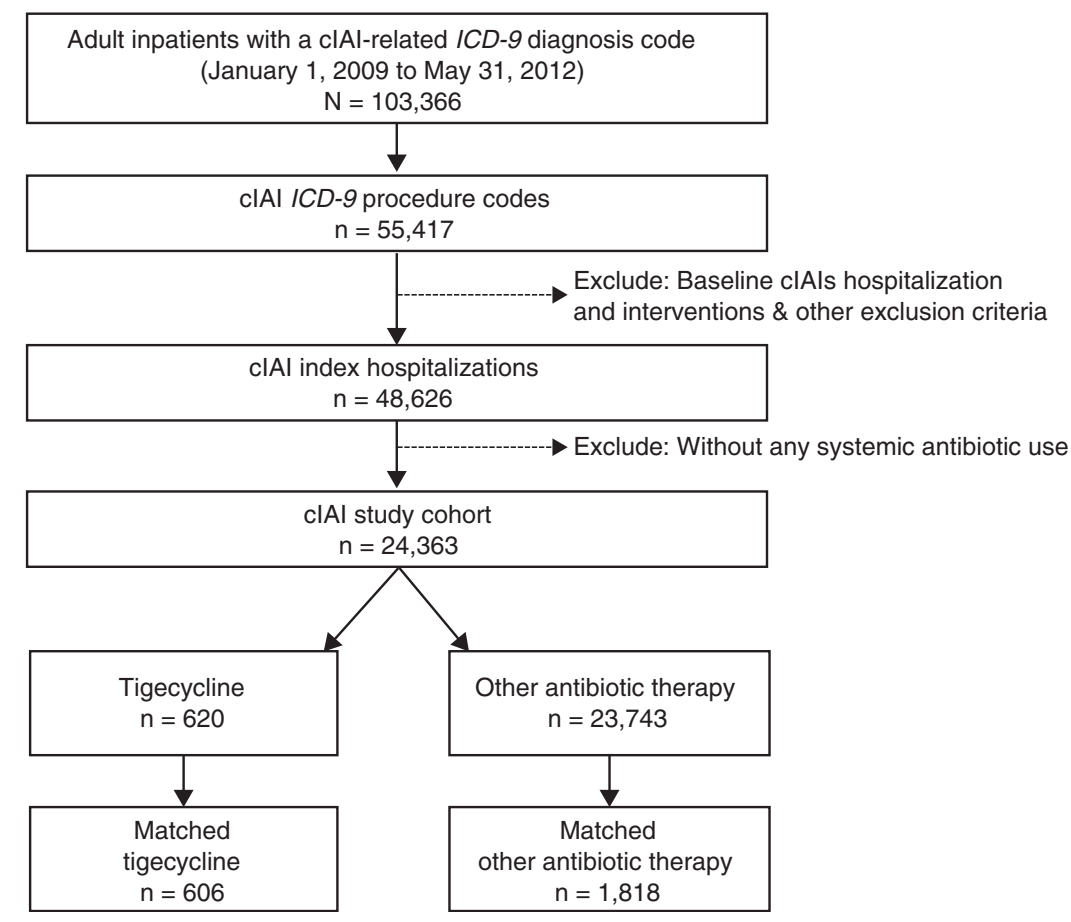

FIG. 1. Study attrition. (cIAI = complicated intra-abdominal infection; ICD-9=International Classification of Diseases, Ninth Revision).

Table 1A. Patient Characteristics Prior to Propensity Score Matching

\begin{tabular}{|c|c|c|c|}
\hline Characteristic $^{\mathrm{a}}$ & Tigecycline $(\mathrm{n}=620)$ & $\begin{array}{l}\text { Other antibiotic } \\
\text { therapy }(\mathrm{n}=23,743)\end{array}$ & $\mathrm{p}$ \\
\hline Mean age (SD), y & $62.5(16.0)$ & $60.6(16.8)$ & 0.0614 \\
\hline Female & $349 \quad(56.3)$ & $12,260 \quad(51.6)$ & 0.0690 \\
\hline White & $452 \quad(72.9)$ & $16,654 \quad(70.1)$ & 0.0770 \\
\hline \multicolumn{4}{|l|}{ APR-DRG severity of illness $b$} \\
\hline Mild (1) & $(0.2)$ & $(0.6)$ & \multirow[t]{4}{*}{$<0.0001$} \\
\hline Moderate (2) & $(10.2)$ & (16.6) & \\
\hline Major (3) & $(28.9)$ & (35.9) & \\
\hline \multirow{2}{*}{\multicolumn{4}{|c|}{$\begin{array}{l}\text { Extreme } \\
\text { APR-DRG risk of death }\end{array}$}} \\
\hline & & & \\
\hline Mild (1) & $(3.5)$ & $(6.8)$ & \multirow[t]{4}{*}{$<0.0001$} \\
\hline Moderate (2) & $114 \quad(18.4)$ & $(24.8)$ & \\
\hline Major (3) & 171 (27.6) & $(32.2)$ & \\
\hline Extreme (4) & $(50.5)$ & $(36.3)$ & \\
\hline \multicolumn{4}{|l|}{ Site of infection } \\
\hline Stomach & $15 \quad(2.4)$ & $(2.2)$ & 0.7613 \\
\hline Appendix & $11 \quad(1.8)$ & ( 2.9) & 0.0874 \\
\hline Liver & $3(0.5)$ & $(0.6)$ & 0.7151 \\
\hline Small intestine & $169 \quad(27.3)$ & (25.5) & 0.3283 \\
\hline Large intestine & $265 \quad(42.7)$ & $(40.2)$ & 0.2052 \\
\hline Pancreas & - & $(0.0)$ & 0.8192 \\
\hline Gallbladder & $33 \quad(5.3)$ & $(8.5)$ & 0.0051 \\
\hline Other abdominal surgery ${ }^{\mathrm{c}}$ & $227 \quad(36.6)$ & (34.9) & 0.3756 \\
\hline Vasopressor use & $255 \quad(41.1)$ & $(32.9)$ & $<0.0001$ \\
\hline Mechanical ventilator use & $261 \quad(42.1)$ & $(30.9)$ & $<0.0001$ \\
\hline
\end{tabular}

${ }^{a} \mathrm{n}(\%)$, except for age.

${ }^{\mathrm{b}}$ Algorithm-based and takes into consideration ICD-9 diagnosis, age, gender, discharge data, and d on mechanical ventilation.

${ }^{\mathrm{c}}$ Includes percutaneous abdominal drainage, re-opening of recent laparotomy site, and re-closure of post-operative disruption of abdominal wall.

$\mathrm{APR}-\mathrm{DRG}=3 \mathrm{M}^{\mathrm{TM}}$ All Patient Refined ${ }^{\mathrm{TM}}$ Diagnosis Related Group; SD=standard deviation. 
Table 1B. Patient Characteristics Following Propensity Score Matching

\begin{tabular}{|c|c|c|c|}
\hline Characteristic $^{\mathrm{a}}$ & Tigecycline $(\mathrm{n}=606)$ & $\begin{array}{c}\text { Other antibiotic } \\
\text { therapy }(\mathrm{n}=1,818)\end{array}$ & $\mathrm{p}$ \\
\hline Mean age (SD), y & $62.5(16.0)$ & $62.2(16.7)$ & 0.6988 \\
\hline Female & $341 \quad(56.3)$ & $1,014 \quad(55.8)$ & 0.8317 \\
\hline White & $440 \quad(72.6)$ & $1,318 \quad(72.5)$ & 0.9581 \\
\hline \multicolumn{4}{|l|}{ APR-DRG severity of illness ${ }^{b}$} \\
\hline Mild (1) & $(0.2)$ & $(0.1)$ & \multirow[t]{4}{*}{0.5392} \\
\hline Moderate (2) & $63 \quad(10.4)$ & ( 9.2$)$ & \\
\hline Major (3) & 178 (29.4) & (27.9) & \\
\hline Extreme (4) & $(60.1)$ & $(62.8)$ & \\
\hline \multicolumn{4}{|l|}{ APR-DRG risk of death ${ }^{b}$} \\
\hline Mild (1) & $(3.6)$ & $(3.0)$ & \multirow[t]{4}{*}{0.6070} \\
\hline Moderate (2) & (18.6) & (17.3) & \\
\hline Major (3) & $(28.2)$ & (27.3) & \\
\hline Extreme (4) & $(49.5)$ & 952 (52.4) & \\
\hline \multicolumn{4}{|l|}{ Site of infection } \\
\hline Stomach & $(2.5)$ & $46 \quad(2.5)$ & 0.9403 \\
\hline Appendix & $(1.8)$ & $(1.0)$ & 0.1057 \\
\hline Liver & $(0.5)$ & $(0.5)$ & 1.000 \\
\hline Small intestine & $(27.2)$ & $(27.8)$ & 0.7932 \\
\hline Large intestine & $(43.1)$ & $(42.8)$ & 0.9245 \\
\hline Pancreas & - & $(0.1)$ & 0.5636 \\
\hline Gallbladder & $(5.4)$ & ( 5.6$)$ & 0.9183 \\
\hline Other abdominal surgery ${ }^{\mathrm{c}}$ & (36.1) & $(36.0)$ & 0.9610 \\
\hline Vasopressor use & $(40.3)$ & (42.7) & 0.2852 \\
\hline Mechanical ventilator use & (41.3) & (42.6) & 0.5688 \\
\hline
\end{tabular}

${ }_{\mathrm{a}}^{\mathrm{a}}(\%)$, except for age.

${ }^{\mathrm{b}}$ Algorithm-based and takes into consideration ICD-9 diagnosis, age, gender, discharge data, and d on mechanical ventilation

${ }^{\mathrm{c}}$ Includes percutaneous abdominal drainage, re-opening of recent laparotomy site, and re-closure of post-operative disruption of abdominal wall.

$\mathrm{APR}-\mathrm{DRG}=3 \mathrm{M}^{\mathrm{TM}}$ All Patient Refined ${ }^{\mathrm{TM}}$ Diagnosis Related Group; SD= standard deviation.

and d on mechanical ventilation; it was applied in this study to the index hospitalization. On the basis of this system, patients are classified into one of four categories $(1=$ minor, $2=$ moderate, $3=$ major, $4=$ extreme) after the end of the hospital stay. The measures reflect the SOI or ROM during that hospital stay. The APR-DRG system clinical model has been extensively reviewed and is updated regularly [10].

Propensity scoring was used to reduce treatment-selection bias introduced by the use of observational data. Propensity scores were generated using multivariable logistic regression. The propensity score represents a patient's probability of receiving a specific treatment, in this case tigecycline, while adjusting for observed covariates [11,12]. Parameters included in the propensity score model are listed in Appendix Table 2.

Tigecycline patients were placed into quintiles based on propensity score and were matched 1:3 using greedy matching techniques based on the propensity score within

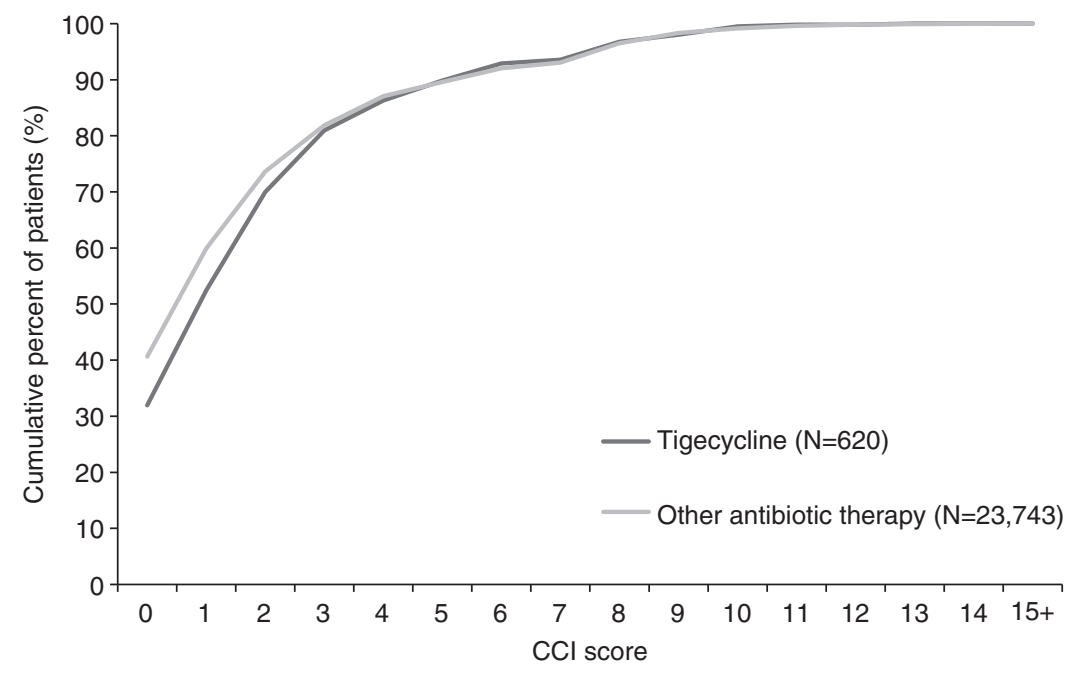

FIG. 2. Distribution of Charlson Comorbidity Index (CCI) scores prior to propensity score matching. 
each quintile to examine outcomes of tigecycline versus other antibiotic therapy [13]. Student $t$-tests and Pearson chisquared tests were used where appropriate to evaluate the effect of treatment defined as success or failure. All analyses were performed using WinSQL (Synametrics Technologies, Inc, Plainsboro, NJ) and SAS v9.2 (SAS Institute, Inc, Cary, NC).

\section{Ethics}

No informed consent was necessary for this database analysis. The database is Health Insurance Portability and Accountability Act (HIPAA)-compliant and has been certified by a third party statistical expert to contain de-identified data. This study was exempt from institutional review board review.

\section{Results}

Of the 103,366 original patients identified by $I C D-9$ code, 620 were included in the tigecycline cohort and 23,743 were included in the other antibiotic therapy cohort (Fig. 1). Patient demographic characteristics were similar across treatment groups. Before propensity score matching, patients in the tigecycline-treated group were more severely ill, having greater APR-DRG SOI and ROM as well as greater use of mechanical ventilation and vasopressors (Table 1A). The CCI scores for both groups are provided in Figure 2. The mean (standard deviation [SD]) CCI score for the tigecycline and other antibiotic therapy cohorts was 2.1 (2.4) and 1.9 (2.5), respectively.

\section{Propensity score-matched population}

The final model based on propensity score matching included 2,424 patients: Tigecycline, $n=606$; other antibiotic therapy, $n=1,818$ (Table 1B). Appendix Table 3 provides a listing of antibiotics included in the other antibiotic therapy population. Following matching, no substantial differences were noted between the treatment groups. Mean (SD) LOS for the index hospitalization was similar between the treatment groups (tigecycline, 11.7 [7.8] d; other antibiotic ther- apy, 11.1 [7.5] d; $p=0.0838)$. Intensive care unit utilization and ICU LOS were also similar. An ICU stay was documented in $91.2 \%$ of tigecycline-treated patients and in $90.2 \%$ of patients receiving other antibiotics, $\mathrm{p}=0.5952$. The mean ICU LOS was $\sim 7 \mathrm{~d}$ for both groups.

Treatment was successful in 426 (70.3\%) tigecyclinetreated patients and in 1,294 (71.2\%) patients receiving other antibiotics. Similar treatment success occurred across all infection sites. Treatment success by APR-DRG was not affected by treatment selection with similar rates of success observed in both treatment groups (Table 2). Success was also not affected by vasopressor or mechanical ventilator use.

Discharge status at $30 \mathrm{~d}$ is presented in Table 3 . No substantial differences in discharge to home health, home or self-care, skilled nursing facility, discharge to rehab facility, or outcome recorded as "expired" were identified between the two treatment groups at $30 \mathrm{~d}$ post-discharge. Treatment failure was associated with a greater need for all-cause re-hospitalization at $30 \mathrm{~d}$ and $180 \mathrm{~d}$ (Fig. 3). However, no difference in cIAI-related re-hospitalization was observed. Figure 4 displays the time course for re-hospitalization. Re-admission related to cIAI was separated out from readmission for all other causes.

\section{Tigecycline-treated comparison with imipenem-cilastatin-treated patient population}

A total of 1,313 patients were included in the analysis (tigecycline, $n=614$; imipenem-cilastatin, $n=669$ ). These patients were not propensity score matched because the number of patients did not permit application of the 1:3 ratio used. However, there is less evidence of a need for propensity score matching because the analysis of the matching criteria did not show substantial differences among the tigecycline and imipenem-cilastatin population in those parameters used for propensity score matching, with the exception of a greater number of females in the tigecycline cohort as well as differences in race (Appendix Table 4).

Mean LOS (SD) was similar between the treatment groups (tigecycline, 11.8 [7.9] d; imipenem-cilastatin, 11.6 [7.8] d; $\mathrm{p}=0.6794)$. Intensive care unit utilization and ICU LOS were

Table 2. Treatment Success among Propensity Score-Matched Patients

\begin{tabular}{|c|c|c|c|}
\hline & $\begin{array}{c}\text { Tigecycline } \\
(\mathrm{n}=606) \mathrm{n} / \mathrm{N}(\%)\end{array}$ & $\begin{array}{l}\text { Other antibiotic therapy } \\
\quad(\mathrm{n}=1,818) n / N(\%)\end{array}$ & $\mathrm{p}$ \\
\hline \multicolumn{4}{|l|}{ APR-DRG severity of illness ${ }^{a}$} \\
\hline Mild (1) & $1 / \quad 1(100)$ & $1 / \quad 1(100)$ & 1.0000 \\
\hline Moderate (2) & $60 / 63(95.2)$ & 159/ 168 ( 94.6) & 0.8559 \\
\hline Major (3) & $152 / 178(85.4)$ & $445 / 508(87.6)$ & 0.4512 \\
\hline Extreme (4) & $213 / 364(58.5)$ & $689 / 1,141(60.4)$ & 0.5263 \\
\hline \multicolumn{4}{|l|}{ APR-DRG risk of death ${ }^{\mathrm{a}}$} \\
\hline Mild (1) & $21 / 22(95.5)$ & $47 / \quad 55(85.5)$ & 0.2173 \\
\hline Moderate (2) & $101 / 113$ ( 89.4$)$ & $284 / 315(90.2)$ & 0.8134 \\
\hline Major (3) & $142 / 171(83.5)$ & $401 / 496(80.8)$ & 0.5248 \\
\hline Extreme (4) & $162 / 300(54.0)$ & $562 / 952(59.0)$ & 0.1237 \\
\hline \multicolumn{4}{|c|}{ Vasopressor/mechanical ventilator use } \\
\hline Vasopressor use & $135 / 244(55.3)$ & $439 / 777(56.5)$ & 0.7476 \\
\hline Mechanical ventilator use & $135 / 250(54.0)$ & $438 / 774(56.5)$ & 0.4734 \\
\hline
\end{tabular}

${ }^{a}$ Algorithm-based and takes into consideration ICD-9 diagnosis, age, gender, discharge data, and d on mechanical ventilation APR-DRG $=3 \mathrm{M}^{\mathrm{TM}}$ All Patient Refined ${ }^{\mathrm{TM}}$ Diagnosis Related Group. 
Table 3. 30-D Discharge Status among Propensity Score-Matched Patients

\begin{tabular}{lcc}
\hline Discharge status & Tigecycline $(\mathrm{n}=606) \mathrm{n}(\%)$ & $\begin{array}{c}\text { Other antibiotic therapy } \\
(\mathrm{n}=1,818) \mathrm{n}(\%)\end{array}$ \\
\hline Discharged to home health & $131(21.6)$ & $404(22.2)$ \\
Discharged to home/self-care & $139(22.9)$ & $503(27.7)$ \\
Discharged/transferred to SNF & $88(14.5)$ & $243(13.4)$ \\
Discharged/transferred to & $23(3.8)$ & $62(3.4)$ \\
$\quad$ another rehab facility & $67(11.1)$ & $186(10.2)$ \\
Expired & $1(0.2)$ & $6(0.3)$ \\
Left AMA & $77(12.7)$ & $170(9.4)$ \\
Still hospitalized & $80(13.2)$ & $244(13.4)$ \\
Other & &
\end{tabular}

${ }^{\mathrm{a}} \mathrm{p}=$ chi-square.

${ }^{b}$ Includes discharges/transfers to short-term general hospitals, intermediate or long-term care facilities, or unspecified locations.

$\mathrm{AMA}=$ against medical advice; $\mathrm{SNF}=$ skilled nursing facility.

also similar between the two groups. Treatment was successful in 429/614 (69.9\%) tigecycline-treated patients and in 479/699 $(68.5 \%)$ imipenem-cilastatin-treated patients. Similar treatment success occurred across all infection sites. Treatment success by APR-DRG was not affected by treatment selection, with similar rates of success observed in both treatment groups (Table 4; both $\mathrm{p}>0.05$ ). Success was also not affected by vasopressor or mechanical ventilator use (both $\mathrm{p}>0.05$ ).

No differences in all-cause re-hospitalization and cIAIrelated re-hospitalization at $30 \mathrm{~d}$ and $180 \mathrm{~d}$ were evident between the treatment groups. Among patients who were considered treatment failures, there was a greater need for allcause re-hospitalization at $30 \mathrm{~d}$ and $180 \mathrm{~d}$ and no difference in cIAI-related re-hospitalization for the same time periods.

\section{Discussion}

Complicated IAIs, as defined in this analysis, are common and important causes of acute morbidity and death. The risk factors identified for poor outcome from the acute infectious process have been well studied and include delay in intervention, advanced age, comorbidity, organ dysfunction, presence of malignant disease, low albumin/poor nutritional status, degree of peritoneal involvement, inability to achieve adequate debridement or control of drainage, and SOI as measured by any of several available scoring systems [3].

An important benefit of current cIAI observational studies is that the data reflect an unselected population of patients meeting disease definitions. Although this accumulates more patients with severe disease, randomization to prevent selection bias is not possible. The prescribing of therapy is based on multiple factors, including the patient's clinical condition, age, comorbidities, geographic region, formulary guidance, and provider preference. Without adjustment for confounding factors, treatment effects are heterogeneous because of patient factors (age, comorbidities, gender, concomitant therapies), and statistical analyses can be distorted [14]. Propensity score matching provides a means to overcome selection bias and allows for determining treatment effects.

In the current study of patients with cIAI, we utilized CCI as a measure of health status combined with the APR-DRG

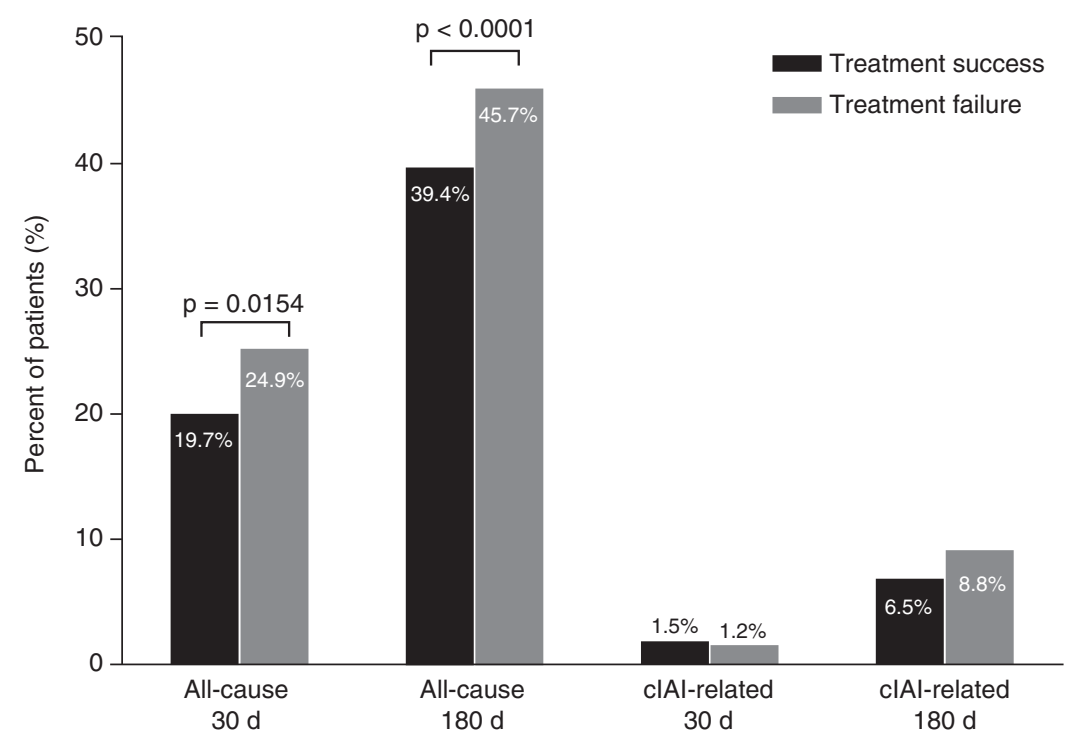

FIG. 3. Re-hospitalization based on treatment success among propensity score-matched patients. (cIAI=complicated intra-abdominal infection). 


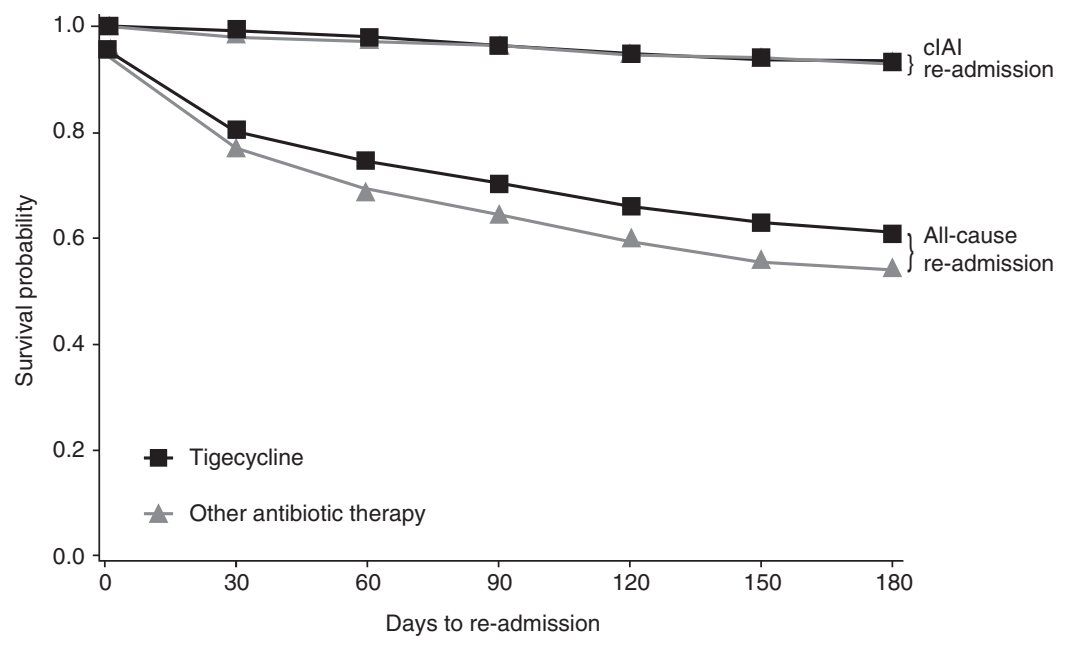

FIG. 4. Time to re-admission. (cIAI=complicated intra-abdominal infection).

system for a measure of SOI and ROM because pre-treatment measures such as APACHE II were not available.

Importantly, we noted substantial differences in the range of diseases treated, demographics, and the outcomes as compared with recently performed randomized registration trials [15-19]. These registration trials included younger patients (mean age $<50$ y) with complicated appendicitis as the most common infection. In addition, patients were not considered severely ill (APACHE II score predominantly $\leq 10)[15-17,19]$.

A key finding of this study was the similar outcomes in both treatment groups in the propensity-matched population and among those considered quite ill. Treatment success was not influenced by site of infection. The analysis of observational data sets matched based on a propensity score in this study overcomes potential bias induced by disease severity and treatment decision factors (as in Table 1A). When we compared outcomes between tigecycline and imipenemcilastatin use, results were similar to those observed in the larger propensity score-matched patient population.

Few data are available examining post-discharge outcomes for patients with cIAI. Patients with cIAI typically are considered as a subset of patients with sepsis. Our data provide important insight into outcomes for patients with cIAI. Only $\sim 25 \%$ of all patients were discharged home to self-care. An additional $\sim 20 \%$ were discharged home but required professional health worker visits. Another $17 \%$ were transferred either to skilled nursing facilities or to other rehab facilities. All-cause re-hospitalization was increased in patients with treatment failure; however, no difference was reported in cIAI-related re-hospitalization between patients who had treatment failure and those with treatment success.

In contrast to our population, long-term outcomes in patients diagnosed with sepsis have been well documented. A systematic review by Winters et al. [20] reported on the longterm mortality rates in patients who had a diagnosis of sepsis or septic shock in 26 studies. Mortality rates after discharge at $1 \mathrm{y}$ ranged from $7 \%$ to $43 \%$. In the observational studies included in this review, mortality rates at $3 \mathrm{~m}$ to $6 \mathrm{~m}$ and $1 \mathrm{y}$ ranged from $3 \%$ to $12 \%$ and $11 \%$ to $42.5 \%$, respectively. The long-term patient outcomes reported in the current study are consistent with reports of patients with sepsis.

The large, multi-center nature of this study using a large healthcare database bolsters the generalizability of the data and study findings. The patients included in our analysis were more severely ill than those typically enrolled in phase 3 clinical trials and are more reflective of patients encountered in standard clinical practice. Use of propensity score

Table 4. Treatment Success Tigecycline versus Imipenem-Cilastatin

\begin{tabular}{|c|c|c|c|}
\hline & Tigecycline $(\mathrm{n}=614) n / N(\%)$ & $\begin{array}{l}\text { Imipenem-cilastatin } \\
(\mathrm{n}=699) n / N(\%)\end{array}$ & $\mathrm{p}$ \\
\hline \multicolumn{4}{|c|}{ APR-DRG severity of illness ${ }^{a}$} \\
\hline Mild (1) & $1 / \quad 1(100.0)$ & $1 / \quad 1(100.0)$ & 1.000 \\
\hline Moderate (2) & $60 / 63(95.2)$ & $53 / 59(89.8)$ & 0.2535 \\
\hline Major (3) & $151 / 177(85.3)$ & $153 / 172(89.0)$ & 0.3100 \\
\hline Extreme (4) & $217 / 373(58.2)$ & $272 / 467$ ( 58.2$)$ & 0.9844 \\
\hline \multicolumn{4}{|l|}{ APR-DRG risk of death ${ }^{\mathrm{a}}$} \\
\hline Mild (1) & $21 / 22(95.5)$ & $19 / 20(95.0)$ & 0.9449 \\
\hline Moderate (2) & $102 / 114(89.5)$ & $99 / 114(86.8)$ & 0.5386 \\
\hline Major (3) & $140 / 168(83.3)$ & $147 / 180(81.7)$ & 0.6828 \\
\hline Extreme (4) & $166 / 310(53.5)$ & $214 / 385(55.6)$ & 0.5920 \\
\hline Vasopressor use & $138 / 254(54.3)$ & $176 / 318(55.3)$ & 0.8084 \\
\hline Mechanical ventilator use & $139 / 258(53.9)$ & $181 / 328(55.2)$ & 0.7524 \\
\hline
\end{tabular}

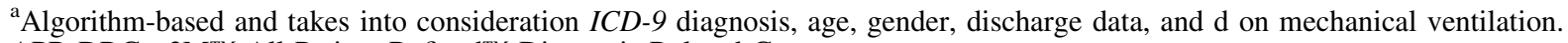
APR-DRG $=3 \mathrm{M}^{\mathrm{TM}}$ All Patient Refined ${ }^{\mathrm{TM}}$ Diagnosis Related Group. 
matching to evaluate the antibiotic therapies in similar patient groups strengthens our findings. The propensity score provided a way to more accurately match patients who had received tigecycline with those who received other agents, in addition to reducing the bias introduced by non-randomized treatment. The unmatched populations showed several differences, including greater SOI and ROM for the tigecyclinetreated patients, and substantially more frequent use of ventilator and vasopressor support. These factors were adjusted by the propensity score matching. Once matching was used and differences between the treatment populations were accounted for, outcome results demonstrated similar success and failure rates across all SOI and ROM ranges. These results suggest that the treatments were similarly effective.

There are important limitations to this study. Firstly, the patients were not randomized to the treatments they received. Although the propensity score accounts for known and observed determinants of outcome, there may well be other unknown risk factors that lead physicians to use one agent versus another. Additionally, a major predictor of treatment failure in patients with cIAI is the timeliness and adequacy of source control. We were not able to evaluate these factors in our study. We cannot comment on the appropriateness in the individual case of tigecycline use. Finally, the data source limitations (e.g., lack of source controls and post-discharge information) only permit an evaluation of short- and longterm real-world outcomes in a large population of relatively sick patients with cIAI.

\section{Conclusions}

With propensity score matching to balance risk of treatment failure, tigecycline-treated patients with diagnosis of cIAI, in our model, were similar to patient populations treated for cIAI with other antimicrobial regimens. Although not propensity score-matched, tigecycline- and imipenem-cilastatin-treated patients were similar enough to allow us to compare outcomes. As with the matched comparison, our data suggest that in patients with more severe cIAI, similar outcomes are also achieved with tigecycline and imipenem-cilastatin treatment.

These data highlight the association between severity of acute illness and outcomes. Using propensity scores to match populations, similar outcomes were demonstrated between treatment with tigecycline and other antibiotics, as expressed by treatment success, similar 30-d discharge status, and the need for re-admission at $180 \mathrm{~d}$.

\section{Acknowledgments}

This study was funded by Pfizer Inc. Mingfang Zhao, a former employee of the Premier, Inc., contributed to the study design and data analysis. Medical writing support was provided by Charlotte Kenreigh of Engage Scientific Solutions and funded by Pfizer Inc.

\section{Author Disclosure Statement}

Drs. Solomkin, Mullins, and Eckmann received remuneration from Pfizer Inc. for their services as members of the Steering Committee for the Tygacil ${ }^{\circledR}$ Observational Study. Dr. Mullins received grant funding from Bayer and Pfizer Inc., and consulting income from Bayer, BMS, Mundi Pharma, Novartis, and Pfizer Inc. At the time of the study, Drs. Ernst and Krukas were full-time employees of the Premier, Inc., which has received financial support from Pfizer Inc. in connection with the study. Dr. Ernst is an employee of Indegene Inc. Dr. Krukas is an employee of Quintiles Inc. Drs. Quintana, Shelbaya, and Reisman are employees of Pfizer Inc.

\section{References}

1. Politano AD, Hranjec T, Rosenberger LH, et al. Differences in morbidity and mortality with percutaneous versus open surgical drainage of postoperative intra-abdominal infections: A review of 686 cases. Am Surg 2011;77:862-867.

2. Solomkin JS. Evaluating evidence and grading recommendations: The SIS/IDSA guidelines for the treatment of complicated intra-abdominal infections. Surg Infect 2010; 11:269-274.

3. Solomkin JS, Mazuski JE, Bradley JS, et al. Diagnosis and management of complicated intra-abdominal infection in adults and children: Guidelines by the Surgical Infection Society and the Infectious Diseases Society of America. Clin Infect Dis 2010;50:133-164.

4. Tygacil [prescribing information]. Philadelphia, PA: Wyeth Pharmaceuticals Inc.;2014.

5. Eckmann C, Montravers P, Bassetti M, et al. Efficacy of tigecycline for the treatment of complicated intraabdominal infections in real-life clinical practice from five European observational studies. J Antimicrob Chemother 2013;68:ii25-35.

6. Sartelli M, Catena F, Ansaloni L, et al. Complicated intraabdominal infections worldwide: The definitive data of the CIAOW Study. World J Emerg Surg 2014;9:37.

7. Sartelli M, Catena F, Ansaloni L, et al. Complicated intraabdominal infections in a worldwide context: An observational prospective study (CIAOW Study). World J Emerg Surg 2013;8:1.

8. Dick A, Liu H, Zwanziger J, et al. Long-term survival and healthcare utilization outcomes attributable to sepsis and pneumonia. BMC Health Serv Res 2012;12:432.

9. Charlson ME, Pompei P, Ales KL, MacKenzie CR. A new method of classifying prognostic comorbidity in longitudinal studies: Development and validation. J Chronic Dis 1987;40:373-383.

10. $3 \mathrm{M}^{\mathrm{TM}}$ APR-DRG Software. Available at: www.solutions.3m .com/wps/portal/3M/en_US/Health-Information-Systems/ HIS/Products-and-Services/Products-List-A-Z/APR-DRGSoftware/. Accessed January 16, 2015.

11. Rosenbaum P, Rubin D. The central role of the propsensity score in observational studies for causal effects. Biometrika 1983;70:41-55.

12. Rosenbaum P, Rubin D. Reducing bias in observational studies using subclassification on the propensity score. J Amer Statistic Assoc 1984;79:516-524.

13. Gu X, Rosenbaum P. Comparison of multivariate matching methods: Structures, distances, and algorithms. J Comput Graph Stat 1993;2:405-420.

14. Stürmer T, Wyss R, Glynn R, Brookhart M. Propensity scores for confounder adjustment when assessing the effects of medical interventions using nonexperimental study designs. J Intern Med 2014;275:570-580.

15. Babinchak T, Ellis-Grosse E, Dartois N, et al. The efficacy and safety of tigecycline for the treatment of complicated intra-abdominal infections: Analysis of pooled clinical trial data. Clin Infect Dis 2005;41:S354-367.

16. Namias N, Solomkin JS, Jensen EH, et al. Randomized, multicenter, double-blind study of efficacy, safety, and 
tolerability of intravenous ertapenem versus piperacillin/ tazobactam in treatment of complicated intra-abdominal infections in hospitalized adults. Surg Infect 2007;8:15-28.

17. Solomkin JS, Yellin AE, Rotstein OD, et al. Ertapenem versus piperacillin/tazobactam in the treatment of complicated intraabdominal infections: Results of a double-blind, randomized comparative phase III trial. Ann Surg 2003; 237:235-245.

18. Solomkin J, Zhao YP, Ma EL, et al. Moxifloxacin is noninferior to combination therapy with ceftriaxone plus metronidazole in patients with community-origin complicated intra-abdominal infections. Int J Antimicrob Agents 2009; 34:439-445.

19. Lucasti C, Jasovich A, Umeh O, et al. Efficacy and tolerability of IV doripenem versus meropenem in adults with complicated intra-abdominal infection: A phase III, prospective, multicenter, randomized, double-blind, noninferiority study. Clin Ther 2008;30:868-883.

20. Winters BD, Eberlein M, Leung J, et al. Long-term mortality and quality of life in sepsis: A systematic review. Crit Care Med 2010;38:1276-1283.

Address correspondence to: Dr. Joseph Solomkin University of Cincinnati College of Medicine 231 Albert B. Sabin Way Cincinnati, $\mathrm{OH}$ 45267-0558

E-mail: solomkjs@ucmail.uc.edu

Appendix Table 1. Diagnosis and Procedure Codes Indicative of Complicated Intra-Abdominal Infections

\begin{tabular}{|c|c|}
\hline ICD-9-CM code & Description \\
\hline \multicolumn{2}{|c|}{ Intra-abdominal infection diagnosis codes } \\
\hline $531.1 \mathrm{x}$ and $531.5 \mathrm{x}^{\mathrm{a}}$ & Gastric ulcer with perforation \\
\hline $531.2 \mathrm{x}$ and $531.6 \mathrm{x}^{\mathrm{a}}$ & Gastric ulcer with hemorrhage and perforation \\
\hline $532.1 \mathrm{x}$ and $532.5^{\mathrm{a}}$ & Duodenal ulcer with perforation \\
\hline $532.2 \mathrm{x}$ and $532.6 \mathrm{x}^{\mathrm{a}}$ & Duodenal ulcer with hemorrhage and perforation \\
\hline $533.1 \mathrm{x}$ and $533.5 \mathrm{x}^{\mathrm{a}}$ & Peptic ulcer with perforation \\
\hline $533.2 x$ and $533.6 x^{a}$ & Peptic ulcer with hemorrhage and perforation \\
\hline $534.1 \mathrm{x}$ and $534.5 \mathrm{x}^{\mathrm{a}}$ & Gastrojejunal ulcer with perforation \\
\hline $534.2 \mathrm{x}$ and $534.6 \mathrm{x}^{\mathrm{a}}$ & Gastrojejunal ulcer with hemorrhage and perforation \\
\hline 540.0 & Acute appendicitis with generalized peritonitis \\
\hline 540.1 & Acute appendicitis with peritoneal abscess \\
\hline 567.x & Peritonitis \\
\hline 569.5 & Abscess of intestine \\
\hline 569.81 & Fistula of the intestine, excluding rectum and anus \\
\hline 569.82 & Ulceration of intestine \\
\hline 569.83 & Perforation of intestine \\
\hline 572.0 & Abscess of liver \\
\hline 575.4 with one of the following: & Acute cholecystitis \\
\hline 574.0 & Calculus of gallbladder with acute cholecystitis \\
\hline 574.3 & Calculus of bile duct with acute cholecystitis \\
\hline 574.6 & Calculus of gallbladder and bile duct with acute cholecystitis \\
\hline 574.8 & Calculus of gallbladder and bile duct with acute and chronic cholecystitis \\
\hline 575.0 & Acute cholecystitis \\
\hline \multicolumn{2}{|l|}{ Surgical procedure codes } \\
\hline $43 . \mathrm{xx}^{\mathrm{b}}$ & Incision and excision of stomach \\
\hline 44. $\mathrm{xx}_{\mathrm{d}}^{\mathrm{c}}$ & Other operations on stomach \\
\hline 45. $\mathrm{xx}^{\mathrm{d}}$ & Incision, excision, and anastomosis of intestine \\
\hline 46. $\mathrm{xx}^{\mathrm{e}}$ & Other operations on intestine \\
\hline 47. $\mathrm{xx}^{\mathrm{f}}$ & Operations on the appendix \\
\hline 50.91 & Percutaneous aspiration of the liver \\
\hline 51. $\mathrm{xx}^{\mathrm{g}}$ & Operations on the gallbladder and biliary tract \\
\hline 52.99 & Operations on the pancreas \\
\hline 54. $\mathrm{xx}^{\mathrm{h}}$ & Other operations on abdominal region \\
\hline 54.12 & Re-opening of recent laparotomy site \\
\hline
\end{tabular}

${ }^{\mathrm{a}} \mathrm{Both}$ codes in the combination are required to indicate the diagnosis specified.

${ }^{\mathrm{b}}$ Codes included 43.5, 43.6, 43.7, 43.81, 43.82, 43.89, 43.91, 43.99.

${ }^{c}$ Codes included 44.00, 44.01, 44.02, 44.03, 44.29, 44.39, 44.5, 44.63.

${ }^{\mathrm{d}}$ Codes included 45.00, 45.01, 45.02, 45.03, 45.61, 45.62, 45.63, 45.71, 45.72, 45.73, 45.74, 45.75, 45.76, 45.79, 45.81, $45.82,45.83$.

${ }^{\mathrm{e}}$ Codes included 46.10, 46.11, 46.13, 46.20, 46.21, 46.23, 46.40, 46.41, 46.71, 46.72, 46.73, 46.74, 46.75, 46.76, 46.79, 46.93, 46.94.

${ }^{\mathrm{f}}$ Codes included 47.01, 47.09, 47.2, 47.91, 47.92, 47.99.

${ }^{\mathrm{g}}$ Codes included 51.21, 51.22, 51.23, 51.24, 51.41, 51.42, 51.43, 51.51.

${ }^{\mathrm{h}}$ Codes included 54.12, 54.61, 54.91.

ICD-9-CM = International Classification of Diseases, Ninth Revision, Clinical Modification. 
Appendix Table 2. Propensity Score Variables

Demographics
Age
Gender
Primary payer
Provider region
Admission source
Hospital
Teaching status
No. of beds
Health status
APR-DRG severity of illness
APR-DRG risk of death
Charlson Comorbidity Index
Vasopressor use
Mechanical ventilator use
Comorbidities
Ever in ICU
Length of stay prior to the index date
Severe sepsis and septic shock

${ }^{\mathrm{a}}$ Myocardial infarction, congestive heart failure, chronic pulmonary diseases, diabetes mellitus or diabetes mellitus with complications, liver or renal diseases.

${ }^{\mathrm{b}}$ During admission date and discharge date.

APR-DRG $=3 \mathrm{M}^{\mathrm{TM}}$ All Patient Refined ${ }^{\mathrm{TM}}$ Diagnosis Related Group; ICU = intensive care unit.
ApPendix Table 3. Other Antibiotic THERAPIES $^{\mathrm{a}}(\mathrm{N}=1,818)$

\begin{tabular}{lr}
\hline & $\mathrm{n}$ \\
\hline Ampicillin & 22 \\
Cefepime & 117 \\
Cefotaxime & 22 \\
Cefoxitin & 141 \\
Ceftazidime & 36 \\
Ceftriaxone & 171 \\
Ciprofloxacin & 374 \\
Clindamycin & 93 \\
Doripenem & 149 \\
Ertapenem & 282 \\
Gentamicin & 151 \\
Imipenem-cilastatin & 134 \\
Meropenem & 126 \\
Metronidazole & 1,085 \\
Moxifloxacin & 70 \\
Piperacillin-tazobactam & 1,071 \\
Ticarcillin-clavulanate & 4 \\
Tobramycin & 45 \\
Vancomycin & 744 \\
\hline
\end{tabular}

${ }^{\mathrm{a}}$ Patients received varying combinations of listed therapies.

Appendix Table 4. Patient Characteristics Imipenem-Cilastatin Comparison (No Propensity Matching)

\begin{tabular}{|c|c|c|c|}
\hline Characteristic $^{\mathrm{a}}$ & Tigecycline $(\mathrm{n}=614)$ & Imipenem-cilastatin $(\mathrm{n}=699)$ & $\mathrm{p}$ \\
\hline Mean age (SD), y & $62.4(16.0)$ & $62.1(15.6)$ & 0.6085 \\
\hline Female & $346 \quad(56.4)$ & $354 \quad(50.6)$ & 0.0386 \\
\hline White & $447 \quad(72.8)$ & $504 \quad(72.1)$ & 0.0059 \\
\hline \multicolumn{4}{|l|}{ APR-DRG severity of illness } \\
\hline Minor (1) & $1 \quad(0.2)$ & $(0.1)$ & 0.1550 \\
\hline Moderate (2) & $(10.3)$ & $(8.4)$ & \\
\hline Major (3) & $(28.8)$ & $(24.6)$ & \\
\hline Extreme (4) & $(60.7)$ & $(66.8)$ & \\
\hline \multicolumn{4}{|l|}{ APR-DRG risk of death } \\
\hline Minor (1) & $(3.6)$ & $(2.9)$ & 0.3745 \\
\hline Moderate (2) & (18.6) & (16.3) & \\
\hline Major (3) & $(27.4)$ & $(25.8)$ & \\
\hline Extreme (4) & $(50.5)$ & $(55.1)$ & \\
\hline \multicolumn{4}{|l|}{ Site of infection } \\
\hline Stomach & $15 \quad(2.4)$ & $(2.0)$ & 0.5882 \\
\hline Appendix & $11 \quad(1.8)$ & $(1.1)$ & 0.3273 \\
\hline Liver & $(0.5)$ & $(0.9)$ & 0.4178 \\
\hline Small intestine & $168 \quad(27.4)$ & $(29.5)$ & 0.3982 \\
\hline Large intestine & $261 \quad(42.5)$ & $(42.1)$ & 0.8697 \\
\hline Pancreas & - & $(0.1)$ & 0.3485 \\
\hline Gallbladder & $33 \quad(5.4)$ & $(6.7)$ & 0.3078 \\
\hline Other abdominal surgery & $(36.8)$ & $(35.5)$ & 0.6170 \\
\hline Vasopressor use & (41.4) & $(45.5)$ & 0.1325 \\
\hline Mechanical ventilator use & $(42.0)$ & $(46.9)$ & 0.0745 \\
\hline
\end{tabular}

\footnotetext{
${ }_{\mathrm{n}}^{\mathrm{n}}(\%)$, except for age.

${ }^{\mathrm{b}}$ Includes percutaneous abdominal drainage, reopening of recent laparotomy site, and reclosure of post-operative disruption of abdominal wall.

APR-DRG $=3 \mathrm{M}^{\mathrm{TM}}$ All Patient Refined ${ }^{\mathrm{TM}}$ Diagnosis Related Group; $\mathrm{SD}=$ standard deviation .
} 